\title{
Effects of Students' Effort Scores in a Structured Inquiry Unit on Long-Term Recall Abilities of Content Knowledge
}

\author{
Sarah Schmid and Franz X. Bogner \\ Z-MNU (Centre of Math \& Science Education), Institute of Biology Didactics, University of Bayreuth, \\ University Campus, NWI, 95447 Bayreuth, Germany \\ Correspondence should be addressed to Sarah Schmid; sarah.schmid@uni-bayreuth.de
}

Received 1 October 2014; Revised 13 January 2015; Accepted 22 January 2015

Academic Editor: Eddie Denessen

Copyright (C) 2015 S. Schmid and F. X. Bogner. This is an open access article distributed under the Creative Commons Attribution License, which permits unrestricted use, distribution, and reproduction in any medium, provided the original work is properly cited.

\begin{abstract}
The influence of students' investment and perception during participation in structured inquiry-based learning on their longterm retention was analyzed to gain more insights into the underlying reasons for long-term retention through structured inquiry learning. Therefore achievement was correlated to effort, lesson rating and perceived competence for learning (PCL), and subject grades. 126 ninth graders participating in a structured inquiry-based interdisciplinary Biology and Physics module were analyzed. Students' knowledge was even measured four times: 2 weeks before, directly after, and six and 12 weeks after module participation. Effort, usefulness, and PCL were observed once, directly after module participation. The invested effort during the lesson correlated positively with the knowledge score measured six weeks and twelve weeks after the lesson. Thus, high effort individuals achieved high knowledge scores at the medium and the long-term measurement. Therefore, effort is a variable that seems to be linked to long-term achievement. Furthermore, Biology and Physics grades reflected individual abilities to acquire long-term knowledge, while a high preknowledge level did not. This result indicates learning strategies as possible core concept underlying individual achievement levels.
\end{abstract}

\section{Introduction}

The literature seems consistent in the fact that learning and achievement are affected by various student attributes (selfconcept, prior abilities, and interest [1]; motivation, values, performance goals, and perceived ability [2]; learning strategies and the impact of learning environment $[3,4]$; social interactions [5]; cognitive strategies, competence, learning goals, and so forth (see, e.g., [6]). Nichols [7] even narrowed the influence down and stated that, besides a variety of factors which are linked to success or failure, the most critical components for success concentrate on attitudes of ability and effort.

In a prior study, we have analyzed the effects of a structured inquiry-based lesson on the achievement of 9th graders. We showed that students increase their content knowledge through the inquiry unit, especially with regard to long-term retention (observed 12 weeks after the lesson) [8]. Therefore, it is of interest now to enquire how students rate certain aspects invested during lesson participation, which may have sustained their learning and long-term retention of content knowledge through structured inquirybased learning. In particular their invested effort and their perceived usefulness of the lesson, as well as how they rated their perceived competence of learning during the inquiry lesson, were measured.

Characteristics of Inquiry-Based Science Courses. According to Yager [5], learning outcomes are interactive results depending on the kind of information encountered and how a student processes it. As learning is the product of self-organization and reorganization, knowledge requires the active participation of the learner. Linn et al. [9] define inquiry as "the intentional process of diagnosing problems, critiquing experiments, and distinguishing alternatives, planning investigations, researching for information, constructing models, debating with peers and forming arguments." Inquiry-based learning tasks are constructed to emphasize independent 
and critical thinking. In inquiry-based teaching students can work rather freely on their tasks, perform experiments handson, and make their own observations and conclusions upon them. The engagement of students with the learning content is multimodal. The learning content often is presented in a way that students can connect it to their everyday life. They also work without tight time constraints and in small groups with their fellows. They take responsibility for their learning. Additionally the teacher does not control every step students take to accomplish a task but encourages students to think of explanations for themselves (problem based thinking). The design of the learning activities and the distribution of authority are important structures in inquiry-based teaching, as these are two pillars of inquiry lessons that differ greatly from traditional, teacher centered lessons. Inquiry-based learning is a teaching approach based on problem-solving strategies [10]. The empowerment of students is taken into account in inquiry-based learning, as the teacher steps back to the role of a guide instead of presenting the center of attention for the classroom, providing all the answers. Inquiry-based learning can be accomplished in several levels in which the pregiven structures by the teacher and the autonomy of the students vary accordingly (see, e.g., [10]). The extremes to both sides have been critiqued: the too tight structures of teacher centered lessons, leaving no room for autonomous student actions and reasoning, as well as open inquiry (sometimes mistaken as discovery learning) with very few predefined structures but very high student autonomy (see, e.g., [11, 12]). However, we agree with Mayer [13] that scaffolding is crucial but that students at the same time need the possibility to learn through active cognitive participation, like in intermediate inquiry levels.

We used the structured form of inquiry-based learning, where students focus on the interpretation of results and the understanding of the linkage between experiment and theory [14]. It is also in line with the benchmarks for science literacy of the American Association for the Advancement of Science [15], enabling students to understand the reasons of an investigation and to analyze claims made from the collected data. Structured inquiry-based teaching is closer to teacher centered teaching on the inquiry-continuum. The teacher provides predefined learning activities with tasks to accomplish and questions to be answered. However, the students need to take responsibility for their learning when working on the material provided. The teacher is not the main actor of a structured inquiry class. Students are encouraged to work without constant guidance from the teacher. In particular they need to draw their own conclusions based on the information read in the provided material and their observations made when conducting experiments. By working in small teams and without constant control from their teacher, students are encouraged to discuss and solve problems with their peers instead of demanding answers from the teacher. By taking responsibility for their learning during a lesson, students should become more independent in reasoning and exploring, thereby engaging in the teaching material more fully, leading them to understand the learning topic and enabling them to recall learned information on the longer term. We decided for structured inquiry-based teaching as the students in our study were not used to inquiry learning. By transferring not too much responsibility to their hands and withdrawing not too much scaffolding from them, the risk of overburdening was meant to be held low.

In inquiry learning, the acquisition of content knowledge is not the only desired outcome, but the fostering of critical thinking and soft skills like participating in a discussion, making observations, relating information read with results obtained from an experiment, working in teams, and handling experimental setups are also regarded as important. However, unfortunately, in school the score in a test remains the main measure of the ability of a child. These tests also mainly ask for content knowledge, which is why we use content knowledge as a measure of what has been learned, although the students most probably gained much more from the lesson than just facts.

\subsection{Mechanisms Underlying Improved Learning through} Inquiry-Based Learning. A crucial element of the learning process in inquiry-based classes could be the motivation to learn and especially the effort students invest into their learning attempts. Motivation to learn science can be defined as an internal state that arouses, directs, and sustains science learning behavior [16]. Effort can be defined as "a vigorous or determined attempt" to achieve something, for example, to achieve understanding the content of the lesson [17]. Motivation had been found to be increased when students learned through inquiry-based learning. For example, Gibson and Chase [18] found that if inquiry-based teaching is used for science teaching, students retain higher interest and also become more motivated to put more effort into their learning. Additionally, Tuan et al. [19] found that inquiry instruction can increase motivation toward science learning more than traditional science teaching.

Nichols [7] suggested that lessons that are based on social relationships and that encourage student autonomy, like inquiry-based lessons do, could lead to an improvement of motivation and achievement. Also Ertepmar and Geban [20] described students in an investigative-group as higher scoring regarding knowledge and comprehension levels than students of a worksheet-group; both authors concluded that problem solving requires more than only the knowledge of facts, since it also requires knowledge about the way information is represented and organized. They argue, furthermore, that the acquisition of concepts is enhanced when students have the opportunity to practice hands-on investigative activities. Nieswandt [21] stated that connecting various isolated pieces of information or applying newly learned information to everyday life phenomena may lead to meaningful conceptual understanding, while, for example, simple recalling may only lead to short-term knowledge. The multimodal nature of inquiry learning might enable students to retrieve learned information more easily, due to better accessibility through various pathways [8]. Lau and Roeser [22] identified engagement as a key mediating process in the commitment pathway linking person variables to achievement outcomes. Tyler et al. [23] also found that tasks requiring higher effort may lead to better recall than tasks requiring a lower level. It therefore seems that effort may play 
a crucial role in the process of understanding and retaining new learning material. In addition to the invested effort during the lesson, we also analyzed students' perceived usefulness of the lesson and their perceived learning competence to gain more insights into which factors might promote longtime retention through participation in structured inquiry learning settings [8].

Consequently, the main objectives of our study focused on the relationship of (i) students' effort, (ii) perceived usefulness of the lesson, and (iii) perceived competence for learning on students' short- and long-term achievement in a structured inquiry intervention about acoustics and the ear. Furthermore, we analyzed the impact of students' grades in Biology and Physics on their short- and long-term achievement (vi). We derive practical advice for teaching structured inquiry-based learning in school as far as the data allow and for knowing which variables can affect learning, since long-term retention may support the classroom of tomorrow, in order to produce better informed students.

\section{Methods and Procedures}

2.1. Participants. Our study followed a four-point testing schedule: pretest, posttest, and two retention tests and followed a quasi-experimental design [24]. Participants were all high-achieving 9th graders (Gymnasium). 126 ninth graders from ten classes $(47.83 \%$ females $)$ participated in our study. The mean age was 15.1 years $(\mathrm{SD}=0.55)$. All students were novices in the subject topic. Before grade 9, namely, in grade 5, students learn about human senses (curriculum reference: nature and technique \#5.2.2) only basically and an introduction to air and sonic (curriculum reference: nature and technique \#5.1.2) is given.

To exclude possible learning effects due to repetitive answering of the knowledge questionnaire, a control group was analyzed. The control group did not participate in the inquiry unit, nor was its learning content similar to the inquiry unit, regarding the whole period of 14 weeks when the knowledge questionnaires were filled in. Furthermore, the control group did not fill in questionnaires concerning directly the inquiry lesson (IMI-E, IMI-V, and PCL; see below). The control group consisted of additional 62 students from 3 classes, with $50.8 \%$ females and a mean age 14.72 years $(S D=0.52)$. An earlier study of Schmid and Bogner [8] revealed that the control group did not learn significantly through completing questionnaires four times. Therefore, learning was due to participation in the inquiry intervention and not (additionally) due to repetitive questionnaire answering. It is provided here for the analysis of the correlation between school grades and knowledge scores. The control group is not established for comparisons of teaching styles, as this is not the focus of this research, but for controlling for learning bias.

2.2. Lesson. The structured inquiry intervention was implemented in three consecutive lesson hours in conventional classrooms. Initially, students were shortly briefed about the intervention: what the broad topic is and that they will work in small teams to discover the topic of sound and human hearing on their own. Questions should only be addressed to the teacher if they could not be solved within the team. Tables were clustered for group work and a workbook, providing background information, describing the hands-on material, and posing questions to be answered was distributed. It was explained that they will encounter experiments as they work through the workbook and that all materials necessary can be found in a big box placed in the middle of the class on an empty desk. During the inquiry lesson, students formed small stable teams of four. Each team member had a special task, for instance, reading the text, fetching the experimental material, conducting the experiment, and writing down the conclusions of the group. Students were asked to rotate the tasks with each new section of the workbook, to ensure that each student would be engaged in the work of the group. Student teams could work self-guided. The teacher's role was a facilitating guiding one, just helping when teams had already discussed the problem but still needed help. Students needed to explain what they had tried unsuccessfully and to suggest ideas about a solution. The teacher never solved a problem directly, but helped them to focus so they could revise their mistake or false conclusions. An extraction of the learning material can be found in the appendix.

2.3. Scales and Questionnaires. A principal axis factoring (PAF) analysis assured constructing validity for both scales applied (IMI and PCL). A direct oblimin rotation was used to simplify interpretation of the factors. Factor loadings above 0.40 were considered as sufficient for including an item [25]. For the internal consistency of each subscale of the instruments (IMI-I, IMI-E, and PCL) Cronbach's alpha was calculated, and values above 0.7 were regarded as reasonable.

Students' intrinsic motivation was measured by applying two subscales of the "Intrinsic Motivation Inventory" (IMI [26]): Effort/Importance (IMI-E) (4 items; Cronbach's alpha $=0.8$; e.g., "I put a lot of effort into this") and Value/Usefulness (6 items; Cronbach's alpha $=0.73$; e.g., "I believe this activity could be of some value to me"). Furthermore, the "Perceived Competence for Learning Scale" (PCL [27]) was applied (4 items, no subscales, Cronbach's alpha $=0.79$; e.g., "I feel confident in my ability to learn this material"). All three instruments were 5-point Likert response scaled, ranging from 1: "not at all true" to 5: "very true". Each of these scales refers to students' opinion during the class, that is, the effort invested in this explicit lesson and not, for example, their general effort for science classes.

Our knowledge questionnaire consisted of 17 multiple choice items with four answer options each, only one of which was correct. Therefore, the maximum knowledge score was 17. The item difficulty [28] ranged between $20 \%$ and $80 \%$. In classical test theory, the mean-item-difficulty is the percentage of participants that answered the item correctly. The average of overall testing time points was $50.3 \%$ (T0 = $30.2 \%, \mathrm{~T} 1=67.0 \%, \mathrm{~T} 2=52.9 \%$, and $\mathrm{T} 3=51.1 \%)$. The multiple choice test had a mean reliability index of 0.67 (Cronbach's alpha; $\mathrm{T} 0=0.63, \mathrm{~T} 1=0.71, \mathrm{~T} 2=0.65$, and T3 $=0.68$ ). All items of the knowledge questionnaire had a positive discrimination index. In order to avoid bias due to repeated application of an identical test [29], we never made students aware of 


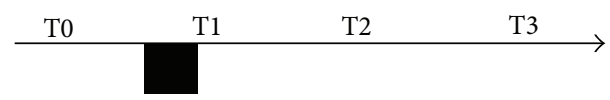

Figure 1: Schedule. Back area: day of lesson. T0: two weeks prior; T1: directly after; T2; six weeks after; and T3: twelve weeks after the lesson.

the testing schedule and analyzed a control group repeatedly answering the questionnaire without participating in the inquiry lesson. Additionally, the order of the questions and the position of the right answer were rearranged randomly for each time point. All questionnaires were paper and pencil tests completed under controlled conditions. The items of knowledge questionnaire are listed in Schmid and Bogner [8].

2.4. Schedule. The schedules for application were about two weeks prior to the school lesson (T0) and directly after the school lesson (T1), as well as six (T2) and twelve weeks (T3) after it (Figure 1). The two subscales of the IMI and the PCL scale were completed once (T1). The test duration was approximately 15 minutes for the three scales together. These scales were embedded into a larger questionnaire which was completed within approximately 40 minutes. Within one year data acquisition was completed.

2.5. Self-Reported Grades. In T0, all students reported their individual grades in the subjects Biology and Physics. Note that the German grading system ranges from 6 (unsatisfactory) to 1 (excellent).

2.6. Statistics. Statistical analysis was carried out using SPSS 20. An alpha value of 0.05 was used as the significance threshold, unless multiple tests were applied. In the case of multiple testing, the alpha-term was corrected following Bonferroni (alpha/number of tests applied). Missing data were excluded list-wise.

\section{Results}

3.1. Analysis of Effort, Usefulness, and Perceived Competence. Gender differences in all three scales (effort, usefulness, and perceived competence) were not observed: sex differences were analyzed using a MANOVA (Pillai's trace $=0.041$, $F(3,122)=1.74, P=$ n.s, partial eta-squared $=0.041, n=$ 126).

3.2. Correlations of the Scales IMI-E, IMI-V, and PCL. The two subscales of the IMI correlate significantly with each other $(P<0.001, r=0.559, n=126)$ and both also correlated with the PCL scale (IMI-E: $P<0.001, r=0.486, n=126$; IMI-V: $P<0.001, r=0.538, n=126)$; see Table 1 . All correlations are positive; that is, when invested effort during the lesson is high, the lesson is also regarded as useful. Students who perceived a high competence for learning the content of the lesson also held high scores of effort and usefulness.

3.3. Knowledge Score, Estimated Effort (IMI-E), Usefulness $(I M I-V)$, and Perceived Competence (PCL). The effort a
TABLE 1: Pearson's correlation coefficients of the three sub-/scales IMI-V, IMI-E, and PCL. The corrected alpha threshold is 0.0167 for the three correlations. $n=126 .{ }^{*} P<0.0167$.

\begin{tabular}{llcc}
\hline & & Usefulness & PCL \\
\hline \multirow{2}{*}{ Effort } & $r$ & $0.559^{*}$ & $0.486^{*}$ \\
& $P$ & $<0.001$ & $<0.001$ \\
\hline \multirow{2}{*}{ Usefulness } & $r$ & 1 & $0.538^{*}$ \\
& $P$ & $/$ & $<0.001$ \\
\hline
\end{tabular}

TABLE 2: Pearson's $r$ for effort, usefulness, and perceived competence on the content knowledge. The corrected alpha value is 0.005 for the following correlations. ${ }^{*} P<0.005$. "n.s." indicates $P$ values above 0.005 .

\begin{tabular}{lcccc}
\hline \multicolumn{1}{c}{ Knowledge score at } & T1 & T2 & T3 \\
\hline \multirow{2}{*}{ Effort } & $r$ & 0.101 & $0.253^{*}$ & $0.253^{*}$ \\
& $P$ & n.s. & 0.004 & 0.004 \\
\hline \multirow{2}{*}{ Usefulness } & $r$ & 0.027 & 0.121 & 0.206 \\
& $P$ & n.s. & n.s. & n.s. \\
\multirow{2}{*}{ PCL } & $r$ & 0.176 & $0.256^{*}$ & 0.233 \\
& $P$ & n.s. & 0.004 & n.s. \\
\hline
\end{tabular}

student invests during the lesson (T1) does not correlate significantly with the knowledge score he or she gains directly after lesson participation (T1) $(P=$ n.s., $r=0.101)$. The same is true for students' estimation of the usefulness of our module $(P=$ n.s., $r=0.027)$ and students' perceived competence $(P=$ n.s., $r=0.176)$. This is probably because, directly after a lesson, most students are able to gain a high knowledge score as the time between the learned material and the knowledge questionnaire is minimal.

A more refined picture is given six weeks after participation (T2). Here, the effort a student took during the lesson correlates highly with his/her knowledge score after six weeks $(P=0.004, r=0.253)$. Thus, students with a high effort score during our module also achieved high knowledge scores in the knowledge test six weeks later, and students with a low effort-value gained a low knowledge score after six weeks. The same is true for students' perceived competence for learning $(P=0.004, r=0.256)$. Is the perceived competence for learning during a lesson high, a high knowledge score is gained after six weeks (and vice versa). However, students' estimation of the usefulness of the lesson does not correlate significantly with the knowledge score even after six weeks $(P=$ n.s., $r=0.121)$.

After twelve weeks (T3) the effort-value during the lesson continues to correlate highly significantly with the knowledge score $(P=0.004, r=0.253)$. The correlation between perceived competence of learning that students reported during our module and their knowledge score after 12 weeks fails to be significant 12 weeks after the lesson $(P=$ n.s., $r=0.233$ ). The students' estimated usefulness of the lesson again does not correlate with knowledge gain after twelve weeks $(P=$ n.s., $r=0.206)$. All correlations are displayed in Table 2, significant correlations are displayed in Figure 2. 


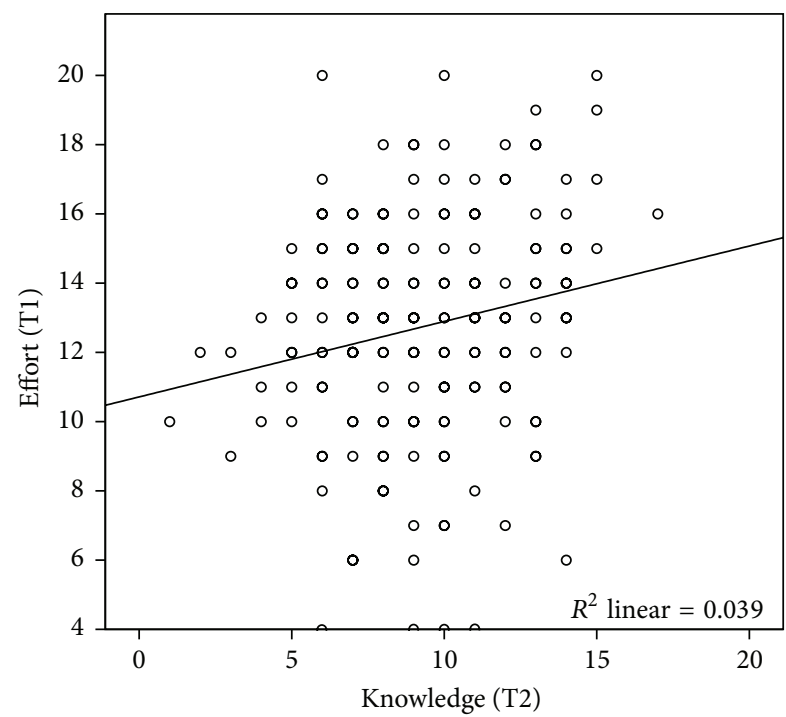

(a)

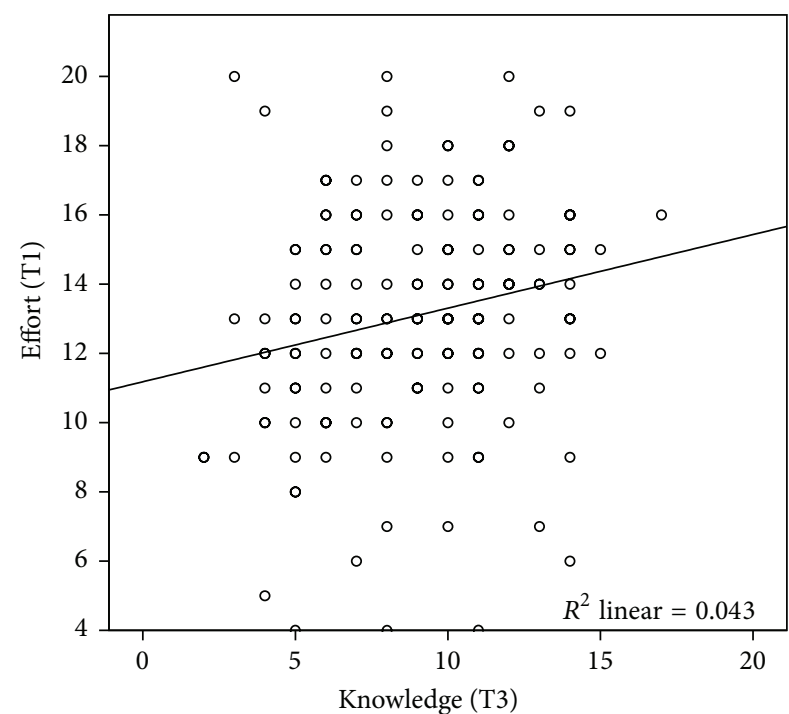

(b)

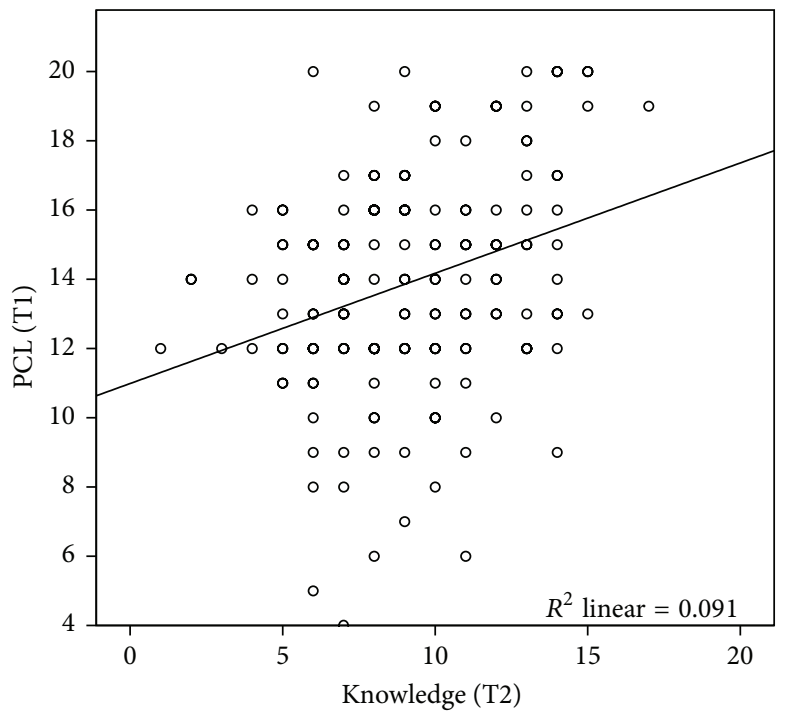

(c)

FIGURE 2: Top: (a) effort during the lesson against the knowledge score after six weeks (T2) and (b) twelve weeks (T3). Bottom: (c) perceived competence for learning during the lesson (PCL) against the knowledge score after six weeks.

3.4. Sex Differences in Grades of Biology and Physics. Sex differences in grades of Biology and Physics were analyzed using MANOVA. There was a significant main effect of students' gender on their grades $F(2,223)=7,25, P=0.001$, partial eta-squared $=0.105$. The effect of gender on the subject grades was revealed for both Biology $(F(1,224)=8.83, P=$ 0.004 , partial eta-squared $=0.066, r=0.26)$ and Physics $(F(1,224)=11.57, P=0.001$, partial eta-squared $=0.085, r=$ 0.10 ). For the grade in Biology, girls (mean $=2.81, \mathrm{SD}=0.955$, $n=62$ ) received worse scores than boys (mean $=2.36, \mathrm{SD}=$ $0.721, n=64$ ), (note that a high grade number indicates a worse grade: the lower the grade number, the better the grade score). The same is true for the grade in Physics (mean boys = $2.39, \mathrm{SD}=0.847, n=64$; mean girls $=2.90, \mathrm{SD}=0.9844$, $n=62$ ). Although boys had better grades in both subjects the small effect sizes and the close means limit the relevance of this finding: the differences between the grades reported by the students may be significantly different from a statistical viewpoint, but the actual "size" is of low importance. Effect sizes can lie between 0 (no effect) and 1 (perfect effect), with effects of $r=0.1$ being a small effect, $r=0.3$ being a medium effect, and $r=0.5$ being a large effect (see [30], page 32). Therefore, grade was not further split up when calculating correlations with achievement.

\section{School Grades and Knowledge Scores}

Preknowledge (T0) does not correlate significantly with the biology grade (Bio: $P=$ n.s., $r=-0.221, n=126$; Phys.: $P=$ $0.008, r=-0.237, n=126)$. This means that students with 
TABLE 3: Students' grades and knowledge scores. The corrected alpha value for the following correlation was 0.0125 . Correlations were calculated according to Pearson. $n=126,{ }^{*} P<0.0125$. "n.s." indicates $P$ values above 0.0125 .

\begin{tabular}{lccc}
\hline Grade & Knowledge score at & T0 & T3 \\
\hline \multirow{2}{*}{ Biology } & $r$ & -0.221 & $-0.237^{*}$ \\
& $P$ & n.s. & 0.008 \\
\hline \multirow{2}{*}{ Physics } & $r$ & -0.213 & $-0.360^{*}$ \\
& $P$ & n.s. & $<0.001$ \\
\hline
\end{tabular}

TABLE 4: Control group students' grade and knowledge scores. The corrected alpha value for the following correlation is 0.0125 . Correlations were calculated according to Pearson. $N=62 .{ }^{*} P<$ 0.0125 . "n.s." indicates $P$ values above 0.0125 .

\begin{tabular}{lccc}
\hline Grade & Knowledge score at & T0 & T3 \\
\hline \multirow{2}{*}{ Biology } & $r$ & -0.151 & -0.071 \\
& $P$ & n.s. & n.s. \\
\hline \multirow{2}{*}{ Physics } & $r$ & -0.074 & -0.160 \\
& $P$ & n.s. & n.s. \\
\hline
\end{tabular}

a high reported grade did not know more about the taught issue than their classmates with a rather low grade in the pretest (T0). However, the long-term knowledge score, after twelve weeks, does correlate with the grades (Bio: $P=0.008$, $r=-0.237, n=126$; Phys.: $P<0.001, r=-0.360, n=126)$. Therefore, students with good subject grades outperformed those with less good grades in the knowledge questionnaire after twelve weeks. In other words, the subject grades reflect very well the ability to learn and to understand information in the long term. The correlations are displayed in Table 3.

The control group did not show any significant correlation between grades and knowledge scores (T0 and T3; see Table 4). Consequently, the positive correlation of grade and long-term acquisition of knowledge within the experimental group was accomplished due to the inquiry lesson and not due to repetitive answering of the same knowledge questionnaire.

\section{Discussion}

5.1. Students' Characteristics Seem to Play Only a Role for Longer-Term Retention. First and foremost, it seems that for the short-term retention (T1) the variables selected in this study may play a minor role since their effect may be overshadowed by the fact that, directly after completion of the lesson, most students were able to gain high knowledge scores, regardless of their effort, value, and perceived competence during the lesson. Thus, teaching for short-termed goals could successfully be applied without considering effort, value, and perceived competence as a major factor for learning. However, the short-term of our investigation refers to the time span between the beginning of the lesson and its end. For the last information worked on, the timespan to handing out the questionnaires could be as few as 5 minutes. Applying a test in school, therefore, should not be used immediately after a lesson, when even low effort produces correct answers. The test results could not be used to differentiate between students that understood the lesson content and those who remembered the facts by heart, as short-term memory apparently seemed sufficient for passing tests then.

Of the three student characteristics monitored during our lesson, effort was the only one that had a positive impact on retention of content knowledge after six and after twelve weeks. This implies that students that made an effort to be good while working in the inquiry lesson were also those that gained the highest knowledge scores up to twelve weeks later. Therefore, students who gave their best during the lesson were the ones that gained the most from the inquiry lesson. What we can conclude from our results is that the amount of effort a student invests during a (inquiry) lesson may predict longterm achievement for up to at least 12 weeks, a relatively long period of time. Graham and Golan [31] showed that students who focus on self-improvement, rather than on comparison with others, exhibit better recall of the learning material. This might also apply to students who attended our inquiry lesson, as they worked in small groups, hindering within-group competition. Furthermore, competition between groups was not encouraged as groups worked independently. Blumenfeld et al. [32] claim that it is not enough to provide students with good learning environments, but that willingness to invest effort to acquire information, generate and test solutions, and evaluate findings is also necessary. With the inquiry unit tested here, students were supported in hands-on learning and encouraged to test their suggestions and ideas for problem-solving. The correlation of effort with the retention of knowledge indicates that students indeed took advantage of the provided structured inquiry learning environment.

It would be interesting to have interviewed our students who stated that they gave little effort in our lesson, and those who reported high effort. In particular the individual learning styles or their approach to a lesson's content could provide important information. Another interesting conclusion is that it seems that there were not many students reaching high knowledge scores without giving much effort; otherwise, a positive correlation of effort and knowledge score would not exist. This would mean that the group contained few students with an already high ability while most students needed to invest high effort to deal with the learning material. Our inquiry unit therefore clearly seems to reach students with willingness for long-term learning; students with less effort tend to reach lower knowledge scores in the long-term. Obviously, students with low effort scores, even within the best learning circumstances, will unlikely achieve meaningful learning levels. Therefore a general positive attitude towards learning with inquiry would be beneficial for the learning process. Students in our study were novices in using inquiry learning. Experts in inquiry-based approaches may have acted differently. Gibson and Chase [18] reported students having higher attitude and interest scores after participation in an inquiry activity and recommended inquiry-based science teaching to produce higher interest and motivation.

If teachers knew about the individual effort levels of students, they could find reasons why effort during a (specific) lesson is not invested. If the short questionnaire about effort 
would be used more frequently in a class, the teacher might discover patterns for example of topics, teaching styles or for example, class-levels why students are (not) willing to invest their effort. If patterns were known in relation to what provokes a majority of students to invest only rather low effort, for example, lessons, topics, teachers, teaching styles, these lessons, and so forth, could be improved accordingly, leading to more involvement in the classroom and thus helping to better retain information in the long term. Building up long-term knowledge is the essential base for connecting new information with that already learned. Only when information can reliably be recalled, students can use it in further lessons and class-levels and connect it to new information. Short-term knowledge, soon forgotten after being learned, is not of much use for preparing students to attend school successfully or for preparing them to be mature citizens. As our structured inquiry intervention led to a link between effort and long-term retention, structured inquiry lessons seem to be a good base for promoting effort and long-term achievement, as well as a good starting point for analyzing which factors of an inquiry instruction evoke higher effort investment in students. For this, careful comparison studies about the many aspects of inquiry-based teaching, one by one, would be beneficial, yet challenging.

The experienced usefulness of a lesson seems not to affect students' knowledge and learning at all, as no significant correlations over the three measuring time points were shown. Therefore, the learning success seems to be independent of a student's evaluation of our lesson. This is in line with Shepardson and Pizzini [33] where students found activities or tasks uninteresting, but engagement was sufficient to promote achievement. They concluded that positive perception towards science activities is not a sufficient indicator of achievement. However, both genders in that study preferred an inquiry-oriented instruction. This result might cheer up teachers who need to teach topics that are less appreciated by the students. Although students might have more and less favored topics and teaching styles, it apparently may neither support nor hinder achievement. However, we monitored only one inquiry module and therefore can say little about whether these implications will hold for other teaching situations. However, others have found that task values predict future course taking better than achievement $[6,34]$.

The perceived competence for learning produced a significant correlation only with the knowledge score obtained six weeks after the lesson ended, but not after 12 weeks. This could imply that the competence students perceived during the lesson was helpful for remembering information at least six weeks later, while twelve weeks later this was no longer the case. Its relation to achievement, therefore, needs to be taken into account. Let us consider the effect of episodic memory: after six weeks students may still remember relatively vividly the circumstances in which they learned the content, while after twelve they might have already filtered the "important" information, the facts and principles taught, and transferred it to their long-term memory. Therefore, perceived competence could have played a role for achievement after six weeks, as students used it as part of their episodic memory to "find" the right answers while "viewing" their memory of the lesson in detail, but not after 12 weeks. The latter time span may be already too long, so students may not "remember" the lesson itself as how (episodic memory) they gained this knowledge, but rather only remembered the information learned, and thus their competence during the lesson was not meaningful at a distant point of retrieving the knowledge information. Further analysis of the PCL, especially concerning effects on retention, should be considered in future research to gain a more concrete picture. As already mentioned, individual interviews could provide answers, maybe as Geier and colleagues [35] did, to obtain more information about the role of episodic memory in the relationship of perceived competence and achievement. Bong and Skaalvik [36] found perceived competence to be a core element of self-concept and selfefficacy beliefs. Similarly, students confident in their abilities have been found to invest more time and energy in learning than students with low self-confidence in their abilities [6]. Others have found that perceived competence is a strong predictor of future science achievement $[34,37]$. Due to these still contradictive findings, the effect of perceived competence on achievement needs attention in further research.

Another explanation may come from the study of Patrick et al. [38] where perceived science competence was shown to rise when the exposure to an inquiry teaching module was lengthened (10 instead of 5 weeks). The fact that our inquiry instruction only lasted for 3 consecutive hours might explain why the correlation between perceived competence and achievement was not significant long-term. Students in our study could perhaps have generated a higher level of perceived competence for learning, if they had have the opportunity to participate in inquiry learning for several days or weeks. However, whether a longer period of time with inquiry learning and an increased PCL would correlate significantly with achievement needs to be tested yet. Conclusions must be restricted to our observation that the reported PCL gained through a 3-hour intervention of inquiry mainly does only partially correlate with students' achievement. This adds to the results of other studies [22, 39] where perceived science competence was a significant predictor of achievement.

Regarding students' subject grades and the correlation to knowledge scores, good grades did not produce higher preknowledge. However, students with good grades outperformed students with low grades in their long-term knowledge scores. In other words, the reported grades of the students fit very well their ability to learn and understand information through the lesson in the long term. Taken together, this implies that students with good subject grades do not have an advantage when starting a new topic because they may already have more knowledge, but rather it is their ability to learn effectively while attending a lesson and in a way that they can retrieve what they have learned after a longer time, even after 12 weeks. This is in line with Lau and Roeser [22] who showed cognitive abilities to be closely associated with students' grades and test scores. Therefore, the use of certain learning strategies might provide a strong predictor for future success and meaningful learning. 


\section{Conclusion}

On the basis of this present study, we can give some insights into what lets a student learn effectively in the long term: structured inquiry-based teaching, high effort, and a good grade in the related subject seem to substantially support long-term retention. From the student characteristics examined in this study, effort during the lesson was shown to be a good predictor of how well a student will do in the next exam in terms of recall ability of the learned material. The more the effort a student gave during the lesson was, the higher his or her knowledge-score was concerning long-term retention of up to twelve weeks. The structured inquiry lesson put the students in the role of actors instead of listeners. It was up to them to get informed about the topic of acoustics and hearing in humans with the information material and the experimental equipment provided. Therefore small groups of students needed to work together. This included reading or listening to the information texts, becoming aware of a phenomenon or problem, catching the right experimental setups and putting them together as mentioned in the text to investigate the phenomenon, to understand what the experiment is about, and to observe results and discuss them within the group to write down a common answer. Supporting student autonomy has been argued to support their natural curiosity for learning (intrinsic motivation) [40]. To support self-determination, Deci and colleagues suggested that choices should be offered, controls minimized, and feelings acknowledged and that information that is needed for decision making and for performing the target task be made available to the student, circumstances often supported by inquiry-based learning instructions. They conclude that providing these circumstances would support educational contexts which facilitate conceptual understanding and flexible problem solving.

As we can see from our present study, structured inquiry learning can not only lead to sustainable knowledge [8], but also reveal long-term acquisition of knowledge as positively linked to students' effort during the inquiry lesson.

We would like to remind readers of Welch's et al. [41] conclusion that a single factor cannot account for all variation in learning, but that there are several factors which seem to influence science achievement. However, effort during class seems to be one factor linked to achievement and retention and, therefore, should be specifically considered when analyzing what it is that makes some students obtain better achievement scores and be able to recall information longer than others.

6.1. Limitations. The results of this study are limited in the way that they reflect a sample of only 126 students of ten classes of one grade level and a single participation in a threehour long lesson that we to our best understanding regard as structured inquiry-based science teaching. Generalization, for example, to other grade levels, other topics, or to student classes that are already used to inquiry-based lessons should not be drawn without precaution. Students used to inquirybased lessons may behave differently than those relatively new to this form of teaching. Whether they would as well invest high effort and therefore gain high content knowledge scores cannot be drawn from our data. It might apply that students new to structured inquiry teaching would invest more effort because the novelty of the learning situation might add to their motivation to explore and learn with it. Students familiar with structured inquiry learning might at some point in time demand for new challenges and therefore invest less effort if bored by scenarios often applied to them. As inquiry-based teaching can be adapted to students' needs, a solution for boredom of the structured way of learning by inquiry could be to allow for more student autonomy, taking the next step to guided inquiry-based learning. Further studies concerning effort investment in different dimensions of inquiry-based learning scenarios are needed before general assumptions can be drawn between the effects of inquirybased teaching on effort investment and its connection to long-term retention of content knowledge.

To only focus on the gain of content knowledge may be regarded as another limitation of this study. As stated in the introduction, inquiry-based teaching holds the potential to not only increase students' knowledge, but moreover support soft skills. These soft skills may be learning how to work in a team, how to discuss, how to handle material, and how to organize procedures and to trust in one's own abilities, to reason logically, and to learn how to explain one's opinion to others or learning to take responsibility for one's learning. Although these soft skills are important goals in class, measuring them is not without problems. We decided for content knowledge, as this is what regular school assessment is mainly made of. However we agree that quantitative analysis can only profit from additional qualitative assessment. Unfortunately it was beyond our feasibilities to record qualitative data of soft skills additionally.

6.2. Outlook for Incorporation of Inquiry-Based Teaching into Today's Schools. To implement structured inquiry-based science lessons in school reality it is important that teachers develop their teaching material accordingly. The creation of inquiry-based learning material may take more time in the beginning, but teaching material at hand can as well be adapted to shorten the design phase. If this extra time in preparation later on saves time during the lesson, as less repetition of content is needed due to better retention, it might even out in the end. Importantly, teachers starting with inquiry teaching should decide for learning goals the class should reach through participation. Inquiry-based science teaching can be adapted to many goals and it spreads from a flowing continuum from very structured to very open. Inquiry-based learning mostly includes the possibility for exploring hands-on experiments to learn about a topic, but the doing of the experiment is not the crucial part; it is the reasoning. As the conduction of experiments in schools can be seen to consist of several "steps," the teacher can make the students focus on one or more steps, depending, for example, on their previous experience. Steps of an experiment may roughly be described as (1) realizing there is an interesting phenomenon to be analyzed, (2) deciding upon a hypothesis to be analyzed, (3) designing an experiment that answers the predefined question, (4) writing down the observations, (5) summarizing the results meaningfully (e.g., bringing them 
in order, creating a table or graph), (6) interpreting the results in the context of background knowledge to clarify the predefined hypothesis (e.g., reading literature), (7) discussing interpretations with peers and, for example, finding a common agreement, and (8) preparing a presentation of the findings. To try to cover all steps within a single lesson is not recommended; instead focusing on certain aspects is the key to introduce inquiry to a class. It helps the teacher to estimate the amount of time needed during the lesson and also makes planning the material more easy as there will be only certain aspects the students will work on fully autonomously. If inquiry learning is taking place more regularly students will probably become confident in their new role as active learners, accepting their responsibility for learning. Second, learning materials need to be designed in a way that they provide structure but yet enable the students to be independent from constant announcements by the teacher on what to do next and enables them to concentrate on the learning material and not the teacher. To judge where to set focusses and what is too less or too much guidance for their classes, teachers need the opportunity to learn this. Regular participation in high quality professional developments needs to be made available if successful implementation of inquiry-based teaching will take place more frequently in classrooms of today and tomorrow.

\section{Appendix}

\section{A. Extraction of the Workbook. Topic 1: "What Is Sound?," Part Four: "Sound Measurement"}

Note that italic written texts under the questions refer to solutions. They were not displayed in the student version distributed to the participating students.

\section{A.1. Sound Measurement. Play the CD with your computer} and watch the video about Visual Analyser, called "VA Video". Visual Analyser is a software program to analyse sounds waves. Do not forget to switch the microphone in the programme in the upper left corner to "ON."

In the upper measurement window of Visual Analyser you see how the air pressure varies with the time on the $x$ axis.

On the vertical $y$-axis you can see the air pressure difference with respect to the normal background air pressure. The maximal pressure difference is the amplitude $(\mathrm{A})$.

On the $x$-axis you see the time.

The presentation of a sound wave in a picture is called graph. It is drawn in a coordination system with $x$ - and $y$ axes. The wave resembles the vibrations of each air particle within a sound wave. (The screenshot from the software has been deleted to prevent copyright conflicts.)

A full vibration is done, when the wave has completed a full cycle. The air particle then has returned to its starting position. A wave in the graph consists of a full hill and a full valley. On which part of the wave the cycle starts does not matter, for example, from one hilltop to the next.
A.1.1. Experiment 3: The Difference between Noise and Tone. You now know enough to start exploring the interesting world of sounds. Paste the screenshot you are asked for in your "screenshot-file" you find on your CD and save it on the desktop. Label it with the date and your group's number, for example, "01.10.2012 - group 2".

A screenshot is made by pressing the "print" button of your keyboard, and right click "paste" afterwards in your screenshot file.

Attention!

(i) Wait one second after making a tone, before you do a screenshot for a better graph.

(ii) Play the metallophone bars softly! Do not strike them with much power!

(iii) If the graph is too small, set the "zoom" from 1 to 5 on the right site of the program.

(iv) Take care of the other groups and only use the instruments for the experiments.

Question: Sonic Can Be Distinguished in Sound and in Noise, But How?

(1) (a) Wrinkle a paper; (b) play a tone on an instrument. Make screenshots for each sound you make. Label each screenshot with the sound you made.

(2) Compare the graphs of the sounds. Which are sounds and which are noises?

Answer: Wrinkling paper is noise.

(3) Describe the differences between graphs of sounds and noises.

Answer: For noise there is no pattern repeating in the graph of the function you can see in Visual Analyser.

We can describe the frequency of a sound. That is what you will find out in the next experiment. For noises on the other hand we cannot calculate a frequency, because they are a more complicated form of sound.

You can link tones to a certain frequency. That is what you can find out in the next experiment. Noises on the other hand are a more complicated kind of sound wave. We cannot link a certain frequency to a noise.

A.1.2. Experiment 4: Frequency. Scientists call the pattern of a sound wave frequency. Each tone has a certain frequency.

The frequency is the number of vibrations per second, and its unit is Hertz $(\mathrm{Hz})$ :

$$
\frac{\text { number of vibrations }}{\text { second }}=\text { frequency. }
$$

You can say that a tone has the frequency of 1 Hertz, meaning it vibrates 1 time per second. 
Question: What Does the Frequency Tell You About the Pitch of a Sound?

Paste the graph of a high and low tone of themetallophone in your screenshot file. Always label which graph is which tone.

(1) Describe the graph of a high tone. Its graph shows a high frequency.

Answer: The pattern is being repeated often within a certain amount of time.

(2) Describe the graph of a low tone. Its graph shows a lower frequency.

Answer: The pattern is being repeated less often within a certain amount of time.

(3) Describe what the frequency informs you about in the context of the pitch of the tone and the number of vibrations in the graph of the sound wave.

Answer: The more the repetitions, the higher the pitch of the tone and the higher the frequency.

(4) What is described when you use the term frequency? Answer: The number of vibrations per second the air particles undergo is what we call frequency.

(5) Which unit does the frequency have?

Answer: Hertz (Hz).

(6) How often does an air particle vibrate when its frequency is 3 Hertz?

Answer: 3 times in a second.

\section{A.1.3. Experiment 6: Amplitude}

Question: What Happens with the Graph When You Play a Tone with Different Loudness?

Paste a screenshot of a loud and less loud played tone on the metallophone to your screenshot file. Make sure to indicate which tone is the softer and which is the louder note in your document. Use the same tone twice.

(1) What is the difference between the graph of the louder and the softer identical tone?

Answer: The graph of the sound wave of the more loud sound shows more deviation in the vertical direction (is higher) than the wave of the more softly played sound.

(2) What does the amplitude inform you about?

Answer: How loud a sound is.

(3) Does the frequency change when the amplitude changes and the other way around?

Answer: No, frequency and amplitude are not dependent.

\section{Disclaimer}

Any opinions, findings, conclusions, or recommendations expressed in this material are those of the authors and do not necessarily reflect the views of the European Commission.

\section{Conflict of Interests}

The authors declare that there is no conflict of interests regarding the publication of this paper.

\section{Acknowledgments}

The authors especially thank the teachers and students contributing to their study. The study was funded by the European Commission (PATHWAY, FP7-Science-in-Society2010-1, THEME SiS-2010-2-2.1-1; 266624).

\section{References}

[1] H. W. Marsh and R. G. Craven, "Reciprocal effects of selfconcept and performance from a multidimensional perspective: beyond seductive pleasure and unidimensional perspectives," Perspectives on Psychological Science, vol. 1, no. 2, pp. 133-163, 2006.

[2] B. A. Greene, T. K. DeBacker, B. Ravindran, and A. J. Krows, "Goals, values, and beliefs as predictors of achievement and effort in high school mathematics classes," Sex Roles, vol. 40, no. 5-6, pp. 421-458, 1999.

[3] R. Garner, "When children and adults do not use learning strategies: toward a theory of settings," Review of Educational Research, vol. 60, no. 4, pp. 517-529, 1990.

[4] C. Ames and J. Archer, "Achievement goals in the classroom: Students' learning strategies and motivation processe," Journal of Educational Psychology, vol. 80, no. 3, pp. 260-267, 1988.

[5] R. E. Yager, "The constructivist learning model: towards real reform in science education," The Science Teacher, vol. 58, no. 6, pp. 52-57, 1991.

[6] J. S. Eccles, A. Wigfield, and U. Schiefele, "Motivation to succeed," in Handbook of Child Psychology, N. Eisenberg and W. Damon, Eds., John Wiley \& Sons, New York, NY, USA, 5th edition, 1998.

[7] J. D. Nichols, "Empowerment and relationships: a classroom model to enhance student motivation," Learning Environments Research, vol. 9, no. 2, pp. 149-161, 2006.

[8] S. Schmid and F. X. Bogner, "Does inquiry-learning support long-term memory?" in Proceedings of the 10th Conference of European Researchers in Didactics of Biology (ERIDOB '14), Haifa, Israel, 2014.

[9] M. C. Linn, E. A. Davis, and P. Bell, Eds., Internet Environments for Science Education, Routledge, London, UK, Lawrence Erlbaum Associates, 2004.

[10] M. R. Blanchard, S. A. Southerland, J. W. Osborne, V. D. Sampson, L. A. Annetta, and E. M. Granger, "Is inquiry possible in light of accountability?: a quantitative comparison of the relative effectiveness of guided inquiry and verification laboratory instruction," Science Education, vol. 94, no. 4, pp. 577-616, 2010.

[11] P. A. Kirschner, J. Sweller, and R. E. Clark, "Why minimal guidance during instruction does not work: an analysis of the failure of constructivist, discovery, problem-based, experiential, and inquiry-based teaching," Educational Psychologist, vol. 41, no. 2, pp. 75-86, 2006.

[12] C. E. Hmelo-Silver, R. G. Duncan, and C. A. Chinn, "Scaffolding and achievement in problem-based and inquiry learning: a response to Kirschner, Sweller, and Clark (2006)," Educational Psychologist, vol. 42, no. 2, pp. 99-107, 2007. 
[13] R. E. Mayer, "Should there be a three-strikes rule against pure discovery learning?" American Psychologist, vol. 59, no. 1, pp. 14-19, 2004.

[14] J. R. Staver and M. Bay, "Analysis of the project synthesis goal cluster orientation and inquiry emphasis of elementary science textbooks," Journal of Research in Science Teaching, vol. 24, no. 7, pp. 629-643, 1987.

[15] American Association for the Advancement of Science, Benchmarks for Science Literacy, Oxford University Press, 1993.

[16] S. M. Glynn, P. Brickman, N. Armstrong, and G. Taasoobshirazi, "Science motivation questionnaire II: validation with science majors and nonscience majors," Journal of Research in Science Teaching, vol. 48, no. 10, pp. 1159-1176, 2011.

[17] Oxford University Press, Effort, 2015, http://www.oxforddictionaries.com/.

[18] H. L. Gibson and C. Chase, "Longitudinal impact of an inquirybased science program on middle school students' attitudes toward science," Science Education, vol. 86, no. 5, pp. 693-705, 2002.

[19] H.-L. Tuan, C.-C. Chin, C.-C. Tsai, and S.-F. Cheng, "Investigating the effectiveness of inquiry instruction on the motivation of different learning styles students," International Journal of Science and Mathematics Education, vol. 3, no. 4, pp. 541-566, 2005.

[20] H. Ertepmar and O. Geban, "Effect of instruction supplied with the investigative-oriented laboratory approach on achievement in a science course," Educational Research, vol. 38, no. 3, pp. 333341, 1996.

[21] M. Nieswandt, "Student affect and conceptual understanding in learning chemistry," Journal of Research in Science Teaching, vol. 44, no. 7, pp. 908-937, 2007.

[22] S. Lau and R. W. Roeser, "Cognitive abilities and motivational processes in high school students' situational engagement and achievement in science," Educational Assessment, vol. 8, no. 2, pp. 139-162, 2002.

[23] S. W. Tyler, P. T. Hertel, M. C. McCallum, and H. C. Ellis, "Cognitive effort and memory," Journal of Experimental Psychology: Human Learning and Memory, vol. 5, no. 6, pp. 607-617, 1979.

[24] D. M. Mertens, Research Methods in Education and Psychology. Integrating Diversity with Quantitative and Qualitative Approaches, Sage, Thousand Oaks, Calif, USA, 2010.

[25] J. P. Stevens, Applied Multivariate Statistics for the Social Sciences, Lawrence Erlbaum Associates, Hillsdale, NJ, USA, 1986.

[26] E. L. Deci and R. M. Ryan, "The general causality orientations scale: self-determination in personality," Journal of Research in Personality, vol. 19, no. 2, pp. 109-134, 1985.

[27] G. C. Williams and E. L. Deci, "Internalization of biopsychosocial values by medical students: a test of self-determination theory," Journal of Personality and Social Psychology, vol. 70, no. 4, pp. 767-779, 1996.

[28] P. Zöfel, Statistik verstehen: ein Begleitbuch zur computergestützten Anwendung, Pearson Deutschland GmbH, Munich, Germany, 2002.

[29] J. P. Keeves, "Methods and processes in research in science," in International Handbook of Science Education, Part Two, B. J. Fraser and K. G. Tobin, Eds., Kluwer Academic Publishers, Dordrecht, Netherlands, 1998.

[30] A. Field, Discovering Statistics Using SPSS Statistics, Sage, London, UK, 2005.

[31] S. Graham and S. Golan, "Motivational influences on cognition: task involvement, ego involvement, and depth of information processing," Journal of Educational Psychology, vol. 83, no. 2, pp. 187-194, 1991.

[32] P. C. Blumenfeld, E. Soloway, R. W. Marx, J. S. Krajcik, M. Guzdial, and A. Palincsar, "Motivating project-based learning: sustaining the doing, supporting the learning," Educational Psychologist, vol. 26, no. 3-4, pp. 369-398, 1991.

[33] D. P. Shepardson and E. L. Pizzini, "Gender, achievement, and perception toward science activities," School Science and Mathematics, vol. 94, no. 4, pp. 188-193, 1914.

[34] A. Wigfield, J. S. Eccles, and U. Schiefele, Development of Achievement Motivation, Academic Press, San Diego, Calif, USA, 2002.

[35] R. Geier, P. C. Blumenfeld, R. W. Marx et al., "Standardized test outcomes for students engaged in inquiry-based science curricula in the context of urban reform," Journal of Research in Science Teaching, vol. 45, no. 8, pp. 922-939, 2008.

[36] M. Bong and E. M. Skaalvik, "Academic self-concept and selfefficacy: how different are they really?" Educational Psychology Review, vol. 15, no. 1, pp. 1-40, 2003.

[37] R. D. Simpson and J. S. Oliver, "A summary of major influences on attitude toward and achievement in science among adolescent students," Science Education, vol. 74, no. 1, pp. 1-18, 1990.

[38] H. Patrick, P. Mantzicopoulos, and A. Samarapungavan, "Motivation for learning science in kindergarten: is there a gender gap and does integrated inquiry and literacy instruction make a difference," Journal of Research in Science Teaching, vol. 46, no. 2, pp. 166-191, 2009.

[39] R. A. Beghetto, "Factors associated with middle and secondary students' perceived science competence," Journal of Research in Science Teaching, vol. 44, no. 6, pp. 800-814, 2007.

[40] E. L. Deci, R. J. Vallerand, L. G. Pelletier, and R. M. Ryan, "Motivation and education: the self-determination perspective," Educational Psychologist, vol. 26, no. 3-4, pp. 325-346, 1991.

[41] W. W. Welch, H. J. Walberg, and B. J. Fraser, "Predicting elementary science learning using national assessment data," Journal of Research in Science Teaching, vol. 23, no. 8, pp. 699706, 1986. 

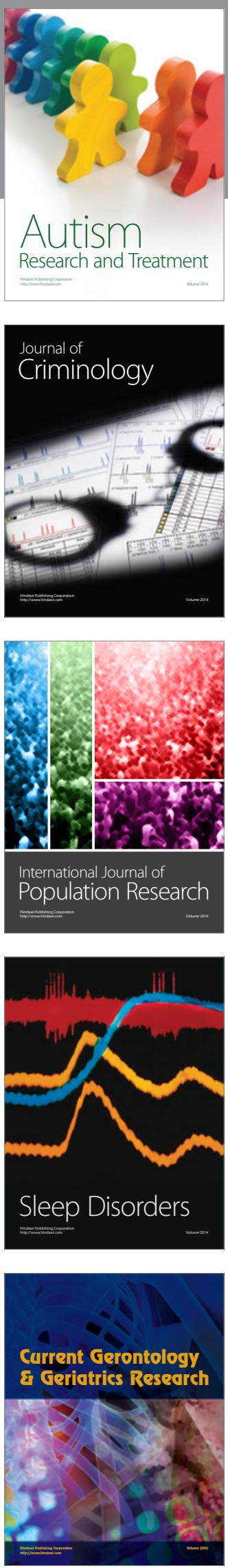
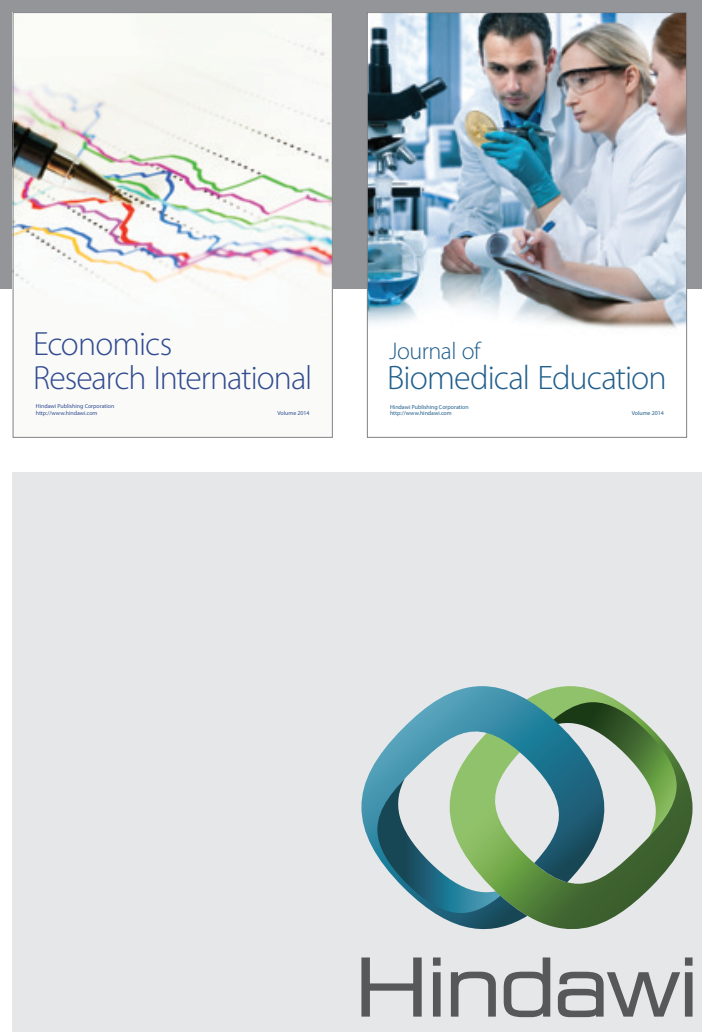

Submit your manuscripts at

http://www.hindawi.com
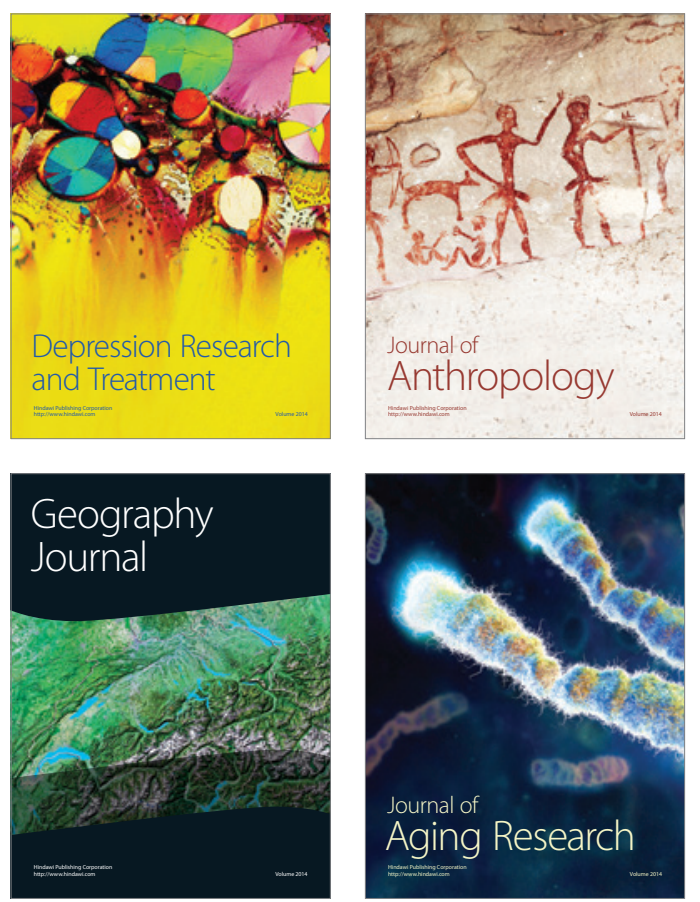
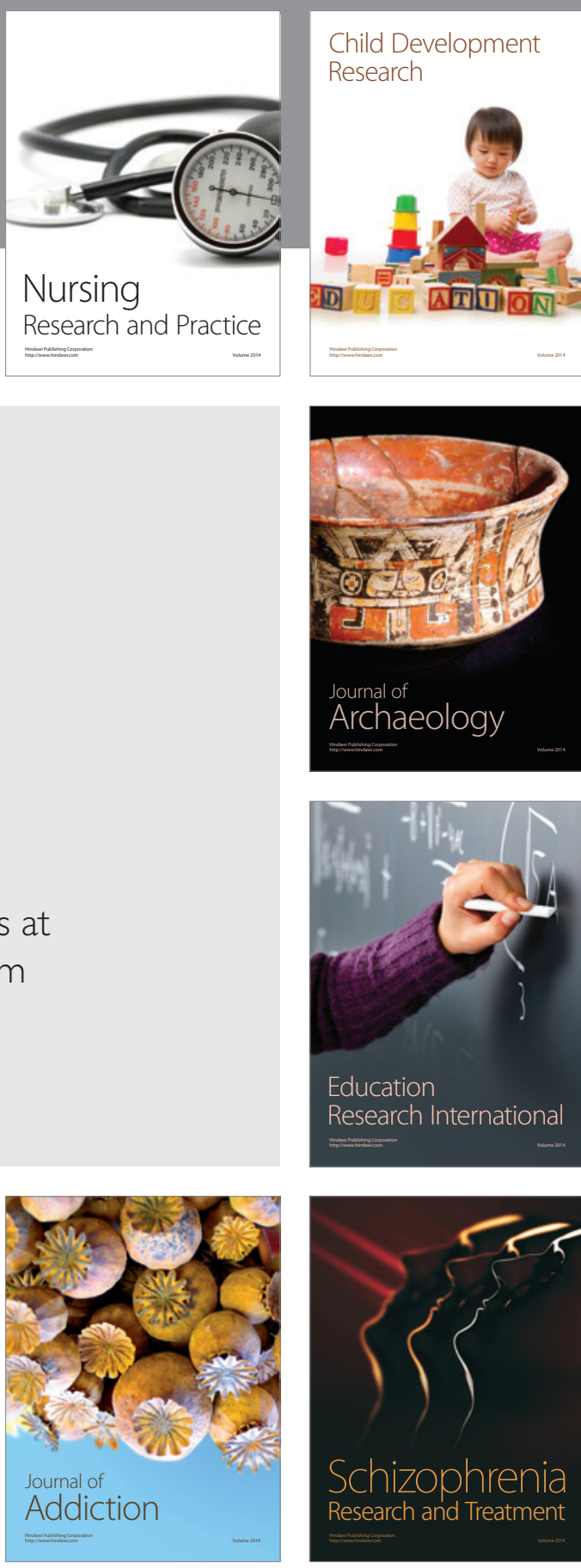

(D)
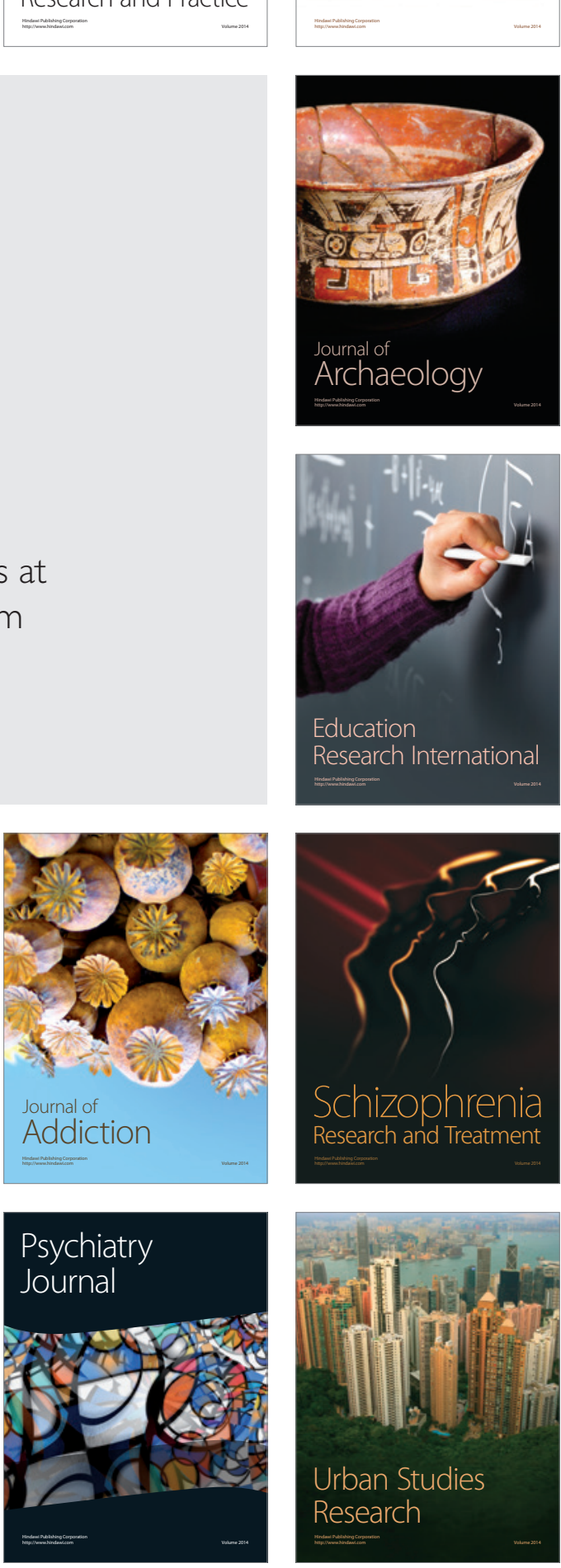